
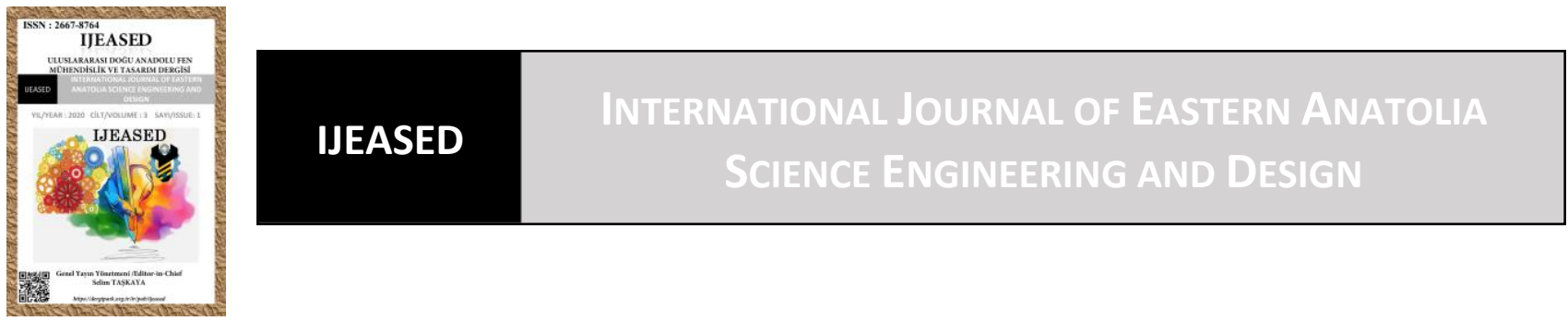

\author{
Uluslararası Doğu Anadolu Fen Mühendislik ve Tasarım Dergisi \\ ISSN: 2667-8764, 3(1), 72-88, 2021 \\ https://dergipark.org.tr/tr/pub/ijeased
}

Araştırma Makalesi / Research Article

Doi: $\underline{10.47898 / \text { ijeased.843773 }}$

\title{
Dişi Defne (Laurus nobilis L.) Genotiplerinde Meyve Yağ Asitleri Kompozisyonlarının Belirlenmesi
}

\author{
Oğuzhan KOÇER ${ }^{1 *}$, Filiz AYANOĞLU ${ }^{2}$
}

${ }^{1}$ Hatay Mustafa Kemal Üniversitesi, Fen Bilimleri Enstitüsü, Tarla Bitkileri A.B.D., Hatay, 31000, Türkiye.

${ }^{2}$ Hatay Mustafa Kemal Üniversitesi, Ziraat Fakültesi, Tarla Bitkileri Bölümü, Hatay, 31000, Türkiye.

\begin{tabular}{l|l|l}
\hline \multicolumn{1}{c|}{ Yazar Kimliği / Author ID (ORCID Number) } & \multicolumn{3}{|c}{ Makale Süreci / Article Process } \\
\hline "Sorumlu Yazar / Corresponding author : & Geliş Tarihi / Received Date $:$ & 20.12 .2020 \\
oguzhankocer@ @otmail.com & Revizyon Tarihi / Revision Date : & 02.01 .2021 \\
\hline iD https://orcid.org/0000-0002-0104-7586, O. Koçer & Kabul Tarihi / Accepted Date : & 03.01 .2021 \\
iD https://orcid.org/0000-0002-3704-0829, F. Ayanoğlu & Yayım Tarihi / Published Date : & 15.07 .2021 \\
\hline
\end{tabular}

Alıntı / Cite : Koçer, O., Ayanoğlu, F. (2021). Dişi Defne (Laurus nobilis L.) Genotiplerinde Meyve Yağ Asitleri Kompozisyonlarının Belirlenmesi, Uluslararası Doğu Anadolu Fen Mühendislik ve Tasarım Dergisi, 3(1), $72-88$.

Özet

Ülkemizde, özellikle Akdeniz, Ege ve Karadeniz bölgelerinde yoğun şekilde bulunan defne (Laurus nobilis L.), Hatay florasında da yaygın bir şekilde elde edilmektedir. Hatay ilinde defne meyvelerinden elde edilen yağ genel olarak sabun üretiminde kullanılmaktadır. Bu çalışmada seçilmiş defne genotiplerin meyve ve yă̆ özellikleri açısından değerlendirilmesi amaçlanmıştır. Bu amaçla, çalışmada Hatay’ın Samandağ ve Yayladağı ilçelerinden ön seleksiyonla seçilmiş 27 dişi defne genotipinin yağ kaliteleri üç tekrarlamalı olarak iki yıl süre ile incelenmiştir. GC/MS analizlerine göre sabit yağların ana bileşenleri ise; oleik asit $(\% 29,92-38,46)$, laurik asit $(\% 10,75$ - 18,69), palmitik asit $(\% 16,31$ $21,97)$ ve linoleik asit $(\% 20,94-24,95)$ olduğu tespit edilmiştir. Sabit yağ oranı yüksek olarak belirlenen ER14 $(\% 32,74)$, ER16 $(\% 31,52)$ ve ER12 $(\% 30,47)$ genotipleri ümitvar genotipler olarak belirlenmiştir.

Anahtar Kelimeler: Defne, Laurus nobilis L., Sabit yağ, Yağ asitleri.

\section{Determination of Fruit Oil Acid Compositions in Female Bay Laurel (Laurus nobilis L.) Genotypes}

\begin{abstract}
In our country, especially in the Mediterranean, Aegean and Black Sea regions, laurel (Laurus nobilis L.) is widely obtained in the flora of Hatay. The oil obtained from the laurel fruits in the province of Hatay is generally used in soap production. In this study, it was aimed to evaluate selected laurel genotypes in terms of fruit and oil characteristics. For


this purpose, the oil qualities of 27 female laurel genotypes selected by pre-selection from Hatay's Samandağ and Yayladağl districts were examined for two years with three replications. According to GC / MS analysis, the main components of fixed oils are; oleic acid (29.92 - 38.46\%), lauric acid (10.75 - 18.69\%), palmitic acid (16.31 - 21.97\%) and linoleic acid (20.94 - 24.95\%) was determined to be. ERI4 (32.74\%), ERI6 (31.52\%) and ER12 (30.47\%) genotypes were determined as promising genotypes, with a high fixed fat content.

Keywords: Bay laurel, Laurus nobilis L., Fixed oil, Fatty acids.

\section{Giriş}

Ülkemizin önemli tıbbi aromatik bitkilerinden olan Akdeniz defnesinin (Laurus nobilis L.) çoğu kaynakta ana vatanı olarak Asya ve Balkanlar gösterilmektedir. Ayrıca, Türkiye başta olmak üzere İspanya, Yunanistan, Fransa, İtalya, Portekiz, Sırbistan, Kosova, Bosna Hersek ve Hirvatistan gibi ülkelerin yer aldığı bölge ile Suriye, Cezayir, Fas, Akdeniz adaları, Kanarya Adaları ve Meksika'da yaygın olarak bulunmaktadır (Ercan, 1983).

Ana yayılış alanı Akdeniz Havzası olan defne, Hatay ilinin sembolü haline gelmiş bir bitkidir. Yurdumuzun bütün sahil kesimi boyunca, başlangıç olarak Hatay olmak üzere Karadeniz'in kuzeydoğusuna kadar yayılım görülmekte olup yaygın olarak görüldüğü yerler Trabzon, Rize, Zonguldak, İstanbul, Balıkesir, Yalova, Bursa, Sinop, Antalya, Muğla, İzmir, Kastamonu, Mersin, Kahraman Maraş ve Hatay olmak üzere, subtropik iklimin etkisi altındaki iç bölgelerde de deniz seviyesinden başlayarak 1200 m yüksekliklere kadar bulunabilmektedir (Davis, 1982; Şafak ve Okan, 2004).

Defne ağacı genellikle 3-8 m yüksekliğinde olup bazen 10 metreyi bulabilen, oldukça sık dallara sahip ve kışın yapraklarını dökmeyen, bir ağaçtır (Şekil 1). Taze sürgünleri yeşil, sonraları siyahımsı kırmızı renkli ve tüysüzdür. Gövde kabuğu koyu gri renkli ve düzgündür. Defne meyveleri ilk zamanlarda yeşil (Şekil 2), sonbaharda olgunlaştığı zaman parlak siyah renklidir (Şekil 3), yaprakları ise üst tarafı parlak ve koyu yeşil, alt yüzü ise donuk yeşildir. Roma rahipleri ve hükümdarları defnenin bekçilik yaptığını düşündükleri için evlerinin önüne defne dikmeyi gelenek haline getirmişlerdir. 


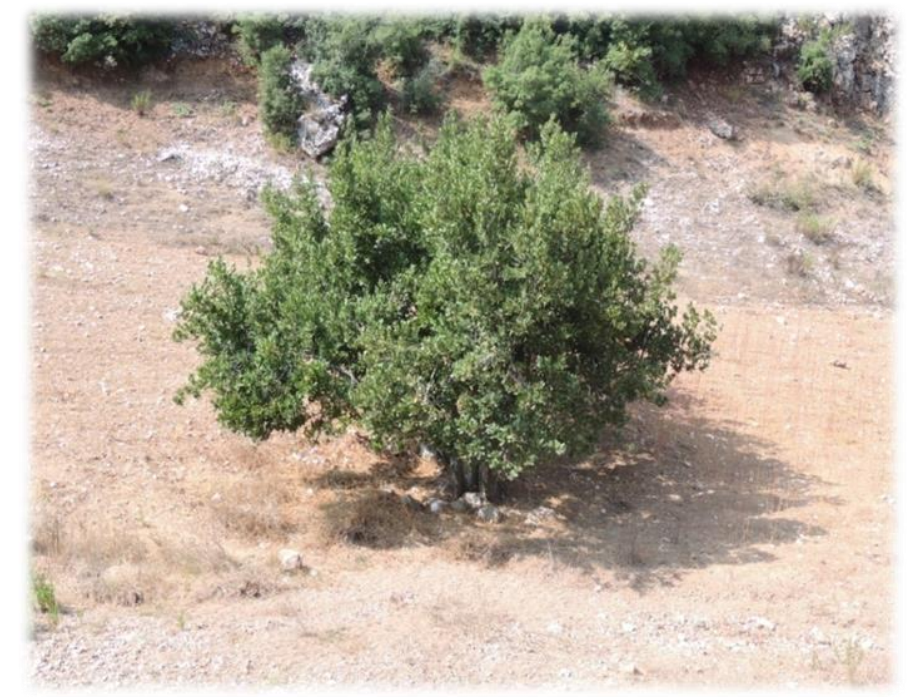

Şekil 1. Doğal yetişmiş defne ağacı

Romalılarda milattan önce 342 yılında altın sikkelerin üzerinde çelenk şeklinde defne figürleri bulunmaktayd1. Eski Mısır ve Asur'da insanlar defneyi şifa hazinesi olarak kabul edip kullanmışlardır. Ayrıca bu bitkinin salgın hastalıkları önlediğine ve yıldırım düşmesi ve şimşek çakmasından da koruduğuna inanırlardı. Peygamberler de seyahatleri sırasında gittikleri bölgelerde ellerinde defne dalı ile gezerlerdi (Duke, 1987; Anonim, 2004; Duke, 2008).

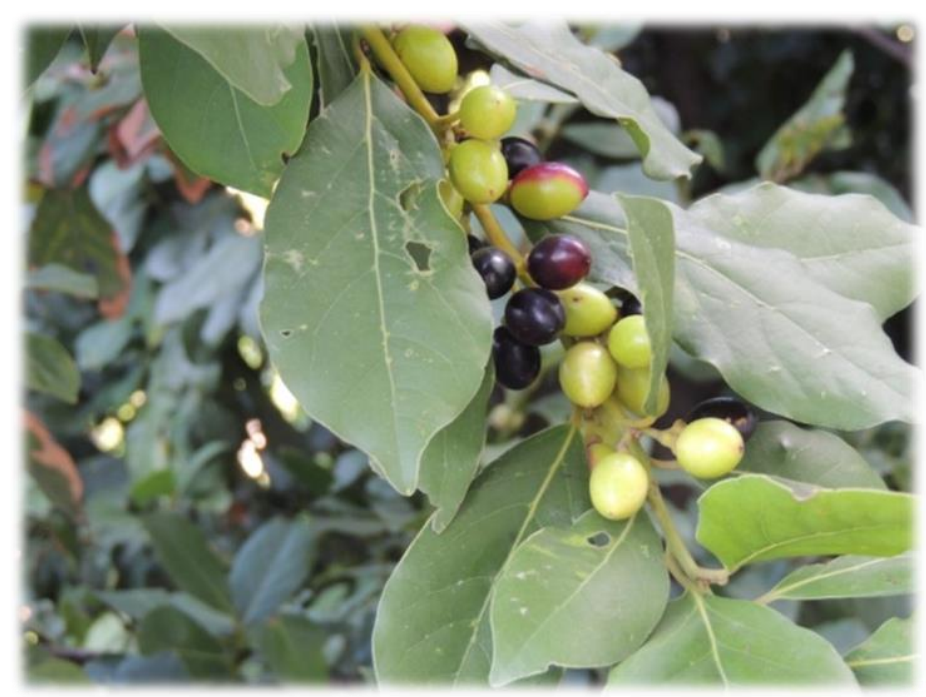

Şekil 2. Yeşil defne meyveleri 


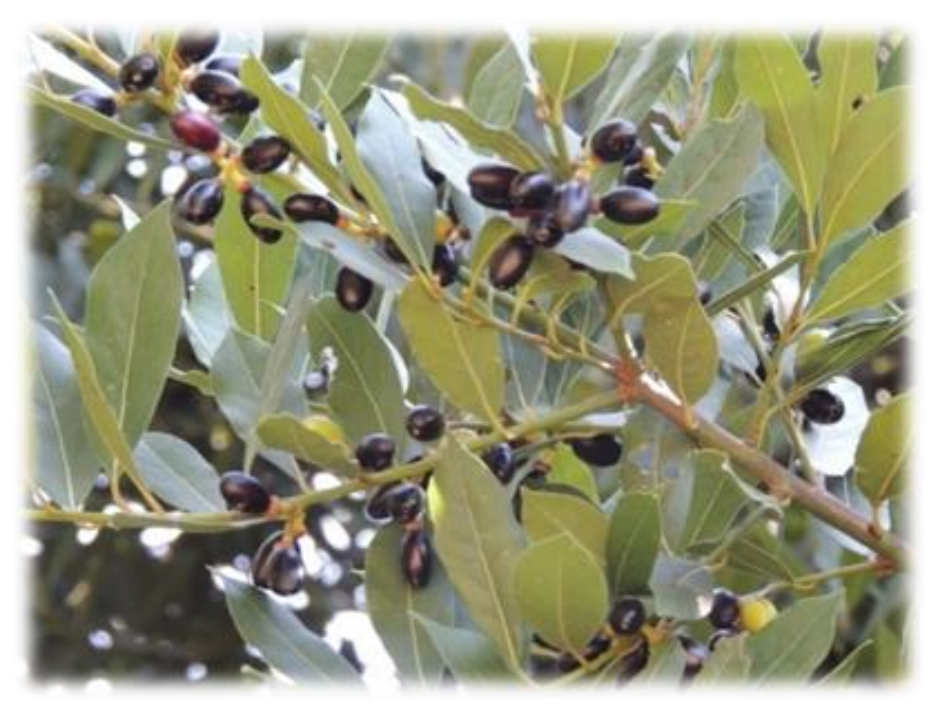

Şekil 3. Olgunlaşmış defne meyveleri

Dış ticaretimizde önemli yer tutan defne yaprakları ve meyvelerinin doğrudan kullanımından ziyade yaprakları ve meyveleri kullanılarak elde edilen uçucu ve sabit yağlar iç ve dış pazarlarda kullanılmaktadır. Defne ve defneden imal edilmiş ürünler gıda, ilaç, kozmetik, kimya gibi birçok alanda kullanılmakta, defnenin hem iç ticareti hem de dış ticareti her yıl daha da artmaktadır. Türkiye, giderek artan talebi ve bu talebin karşılanması açısından en avantajlı ve en yüksek potansiyelli ülkedir. Halihazırda Türkiye kuru defne yaprağının dünyadaki en önemli üreticisi, aynı zamanda da satıcısıdır. (Anonim, 2016; Konukçu, 2001).

Son yıllarda diğer ülkelerden, ülkemizdeki defne yaprağına karşı rağbette artış olduğu görülmektedir. Büyüyen bu pazarda ülkemizin liderliğini koruması, pazarın diğer ülkelere kaymaması için üretim maliyetlerinin düşürülmesi ve defne hasadının daha kaliteli yapılması gerekmektedir. Defne gerek sosyal gerek de ekonomik açıdan odun dışı bir üründür. Bundan dolayı potansiyeli fark edilerek üretiminin ve hasadının iyileştirilmesi gerekmektedir. Kullanım alanları bakımından giderek çeşitlenen ve gelişen bir dağılım gösterdiği için işlenmemiş ürün ticareti ile birlikte katma değeri yüksek ürünlerin üretimi de geliştirilerek defnenin ticari pazarı büyütülmelidir. Defne yaprağı ithal edilen ülkelerin ilk sıralarında Hong Kong, Amerika Birleşik Devletleri, Almanya ve Brezilya gelmektedir. Bunun yanı sıra defne meyveleri ile özellikle Hatay yöresinde geleneksel yöntemlerden suyla kaynatma, sıkma yöntemleri kullanılarak sabit yăg üretilmektedir. $\mathrm{Bu}$ yağ, sabun imalatında ve kozmetik sektöründe kullanılmak için öncelikle Arap ülkelerine gönderilmektedir. (Anonim, 2016). 
Yağ bitkilerinin yăg asitleri kompozisyonu sürekli sabit olmayıp; türlere özgü karakteristik farklılıklar gösterdiği gibi, birçok faktöre bağlı olarak sürekli değişmektedir. Yapılan çalışmalar defne genotipleri arasında yă̆ asitleri bakımından büyük farklılıklar olduğunu ortaya koymuştur. $\mathrm{Bu}$ nedenle bu çalışma gerek yağ içerikleri gerekse yağ asitleri kompozisyonları açısından bölgenin potansiyelinin değerlendirilerek ümitvar genotiplerin belirlenmesinin defne meyvesi üretimi açısından önemli bir adım olacağı düşüncesiyle planlanmıştır. Yağların kalitesini içerdikleri yağ asitlerinin oranları ve kompozisyonu belirlemektedir. $\mathrm{Bu}$ nedenle, yağ bitkilerinin yağ asitleri kompozisyonunda hangi koşullarda nasıl bir değişim meydana geleceğinin bilinmesi, yağ kalitesi açısından önemli olmaktadır. Yağın kalitesi, besleme, teknolojik ve işleme değerleri yağ asitlerinin yağdaki dağılımı ve pozisyonu ile yakından ilgilidir. Bu nedenle çalışmada ayrıca dişi defne genotiplerinde farklı hasat dönemlerine göre sabit yağlarında ontogenetik varyabilitenin belirlenmesi, yağ asitleri kompozisyonunda meydana gelebilecek değişikliklerin ortaya konulması ve uygun hasat döneminin belirlenmesi amaçlanmıştır.

\section{Materyal ve Metot}

\subsection{Materyal}

Çalışmada 2010 yılında TÜBİTAK (Proje No: 1080878) destekli yürütülen bir defne seleksiyonu projesinde (Ayanoğlu ve ark., 2010) Hatay ili Samandağ ve Yayladağı ilçe ve köylerinde doğal olarak yetişen defne popülasyonu arasından bazı üstün özelliklerinden dolayı (meyve iriliği, sabit yağ oranı, yağ asitleri içerikleri vb.) ön seleksiyonda seçilmiş 23 genotip ile daha sonra yapılan arazi çalışmalarında tespit edilen 4 genotip (ŞO1, ŞO2, YT1 ve YT2) materyal olarak kullanılmıştır. Bu dört genotip özellikle yüksek meyve verimleri ile dikkat çekmiştir. Böylece denemede toplam 27 dişi defne genotipi materyal olarak kullanılmıştır. Çalışmada kullanılan defne genotiplerinin konumları ve deniz seviyesinden yükseklikleri (Tablo 1; Şekil 4) kaydedilmiştir. Çalışmada yer alan defne genotiplerinin tamamı ekonomik verim yaşında olan dişi bitkilerden oluşmaktadır. 
Koçer, O., ve Ayanoğlu, F., Uluslararası Doğu Anadolu Fen Mühendislik ve Tasarım Dergisi / International Journal of Eastern Anatolia Science Engineering and Design (IJEASED)

(2021) 3(1):72-88

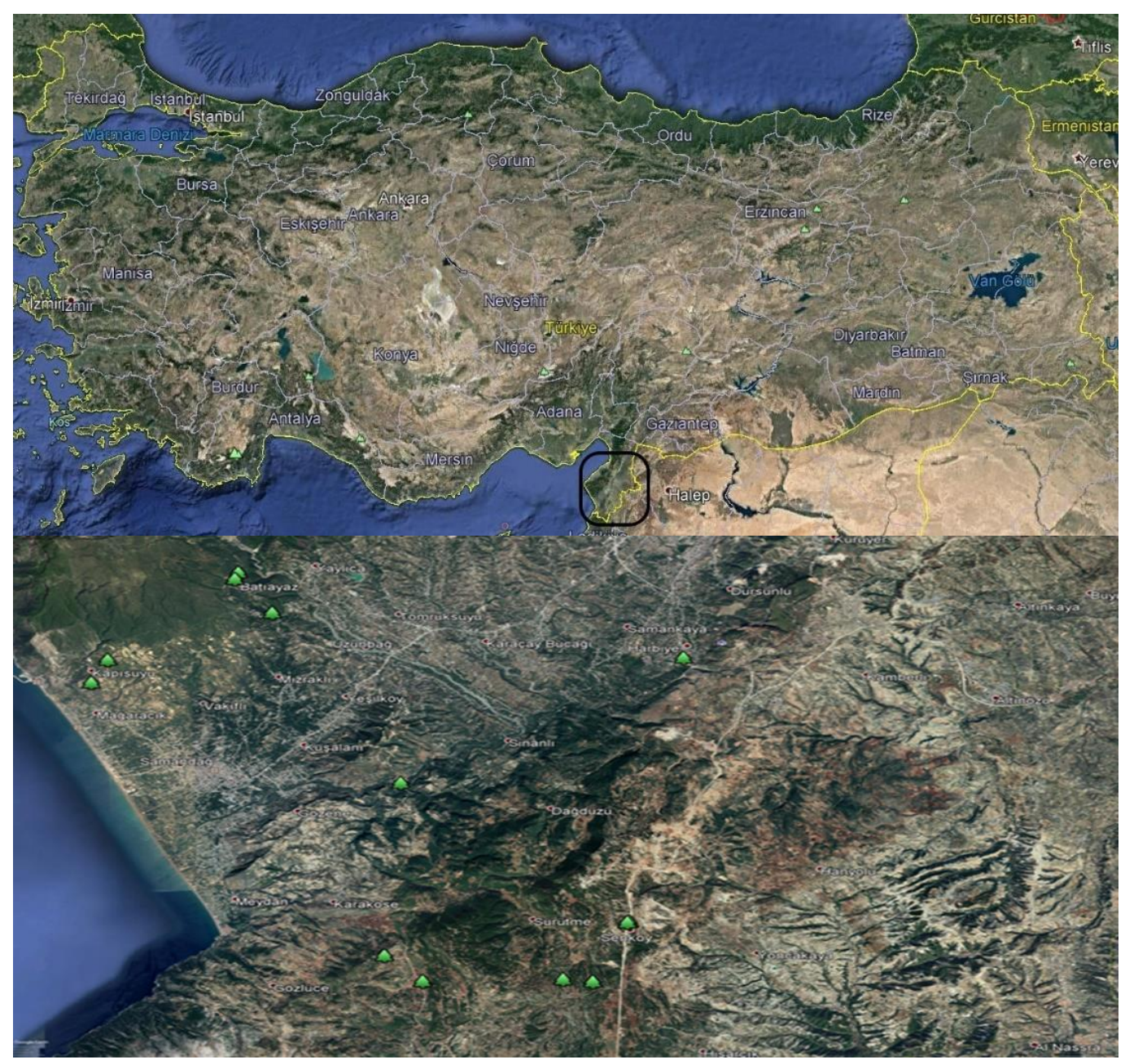

Şekil 4. Seçilen genotiplerin harita üzerindeki yerleri 
Tablo 1. Seçilen defne genotiplerinin kodu, lokasyonu, koordinatı ve rakımı

\begin{tabular}{|c|c|c|c|}
\hline Bitki Kodu & Lokasyon & Rakım (m) & Koordinatlar \\
\hline B3 & Batıayaz & 458 & $\mathrm{~N}: 36.09844-\mathrm{E}: 035.59 \ldots$ \\
\hline B5 & Batıayaz & 460 & $\mathrm{~N}: 36.09851-\mathrm{E}: 035.59 \ldots$ \\
\hline B26 & Batıayaz & 454 & $\mathrm{~N}: 36.09823-\mathrm{E}: 035.59 \ldots$ \\
\hline HB5 & Batıayaz & 488 & $\mathrm{~N}: 36.10081-\mathrm{E}: 035.59 \ldots$ \\
\hline HB7 & Batıayaz & 478 & $\mathrm{~N}: 36.10088-\mathrm{E}: 035.59 \ldots$ \\
\hline HB10 & Batıayaz & 481 & $\mathrm{~N}: 36.10077-\mathrm{E}: 035.59 \ldots$ \\
\hline ER12 & Eriklikuyu & 275 & $\mathrm{~N}: 36.09039-\mathrm{E}: 03600 \ldots$ \\
\hline ER13 & Eriklikuyu & 275 & $\mathrm{~N}: 36.09040-\mathrm{E}: 036.00 .$. \\
\hline ER14 & Eriklikuyu & 275 & $\mathrm{~N}: 36.09040-\mathrm{E}: 036.00 .$. \\
\hline ER16 & Eriklikuyu & 276 & $\mathrm{~N}: 36.09041-\mathrm{E}: 036.00 .$. \\
\hline ER17 & Eriklikuyu & 279 & $\mathrm{~N}: 36.09042-\mathrm{E}: 036.00 \ldots$ \\
\hline ER24 & Eriklikuyu & 283 & $\mathrm{~N}: 36.09050-\mathrm{E}: 036.00 .$. \\
\hline ER42 & Eriklikuyu & 295 & $\mathrm{~N}: 36.09097-\mathrm{E}: 036.00 .$. \\
\hline K1 & Kapisuyu & 130 & $\mathrm{~N}: 36.07204-\mathrm{E}: 035.56 .$. \\
\hline K2 & Kap1suyu & 128 & $\mathrm{~N}: 36.07207-\mathrm{E}: 035.56 .$. \\
\hline K9 & Kapisuyu & 320 & $\mathrm{~N}: 36.07789-\mathrm{E}: 035.57 .$. \\
\hline K13 & Kap1suyu & 132 & $\mathrm{~N}: 36.07211-\mathrm{E}: 035.56 .$. \\
\hline SY9 & Samandağ 1 & 21 & $\mathrm{~N}: 36.05344-\mathrm{E}: 036.03$. \\
\hline SY12 & Samandağ 1 & 22 & $\mathrm{~N}: 36.04449-\mathrm{E}: 036.02$. \\
\hline YY4 & Yayladağı & 933 & $\mathrm{~N}: 36.00779-\mathrm{E}: 036.07 .$. \\
\hline YY9 & Yayladağ & 947 & $\mathrm{~N}: 36.00761-\mathrm{E}: 036.07 .$. \\
\hline YY10 & Yayladağ & 947 & $\mathrm{~N}: 36.00767-\mathrm{E}: 036.07 .$. \\
\hline ŞO1 & Şakşak & 933 & $\mathrm{~N}: 35.59219-\mathrm{E}: 036.06$. \\
\hline ŞO2 & Şakşak & 853 & $\mathrm{~N}: 35.59264-\mathrm{E}: 036.05$. \\
\hline YT1 & Yeşiltepe & 694 & $\mathrm{~N}: 35.59887-\mathrm{E}: 036.02 .$. \\
\hline YT2 & Yeşiltepe & 696 & $\mathrm{~N}: 35.59895-\mathrm{E}: 036.02 .$. \\
\hline 08 & Yeşiltepe & 674 & $\mathrm{~N}: 35.59190-\mathrm{E}: 036.03 .$. \\
\hline
\end{tabular}

\subsection{Metod}

Çalışmada meyve sabit yağı bileşenlerini belirlemek amacıyla 27 farklı defne genotipinden her bir ağacın dört bir tarafından alınan meyve, meyve eti ve çekirdeklerinde ayrı ayrı ekstraksiyon yöntemi ile yağları elde edilerek sabit yağ asitleri kompozisyonları belirlenmiştir. Bu araştırmanın yağ asitleri kompozisyonunu belirleme çalışması ve diğer bütün inceleme ve analizler Hatay Mustafa Kemal Üniversitesi Tarla Bitkileri Bölümü laboratuvarında yürütülmüştür.

Çalışmada sabit yağ eldesi, numunenin çözücü (hekzan) ile ekstraksiyon sonucu çözücünün uzaklaştırılması ve geride kalan kalıntının (defne sabit yağı) tartılması ilkesine dayanmaktadır. Defne meyvesinden çekirdekleri ayrılmış, $70{ }^{0} \mathrm{C}$ sıcaklıkta etüvde kurutularak iyice homojen hale 
getirilinceye kadar öğütülmüş ve bu örneklerden $5 \mathrm{~g}$ numune alınarak soksolet kartuşuna konulmuştur (Şekil 5). Hazırlanan kartuş otomatik soksolet cihazının ekstraksiyon bölümünün içerisine yerleştirilmiştir. Sabit tartıma getirilmiş ekstraksiyon için kullanılacak olan beherlere hekzan eklenerek $\left(\mathrm{M}_{1}\right)$ ekstraksiyon tüpünün altına yerleştirilip ekstraksiyon işlemine başlanmıştır. Ekstraksiyon sonunda içinde yağ bulunan beher alınarak $80^{\circ} \mathrm{C}^{\prime}$ ye ayarlı etüvde 1 saat tutulmuştur. Desikatörde sabit tartıma gelinceye kadar bekletilerek son tartım alınmıştır $\left(\mathrm{M}_{2}\right)$. Aşağıdaki formülle de \% yağ oranı hesaplanmış olup işlemler üç tekrarlamalı olarak yapılmıştır.

$\% \mathrm{Yag}=\left[\left(\mathrm{M}_{2}-\mathrm{M}_{1}\right) / \mathrm{m}\right] \times 100$

$\mathrm{M}_{1}=$ Sabit tartıma getirilmiş beherin ağırlı̆̆ $\mathrm{g}$

$\mathrm{M}_{2}=$ Sabit tartıma getirilmiş beherin ağırlığ $1+$ Kalıntı ağırlı̆̆

$\mathrm{m}=$ Alınan örneğin ağırlığı, g

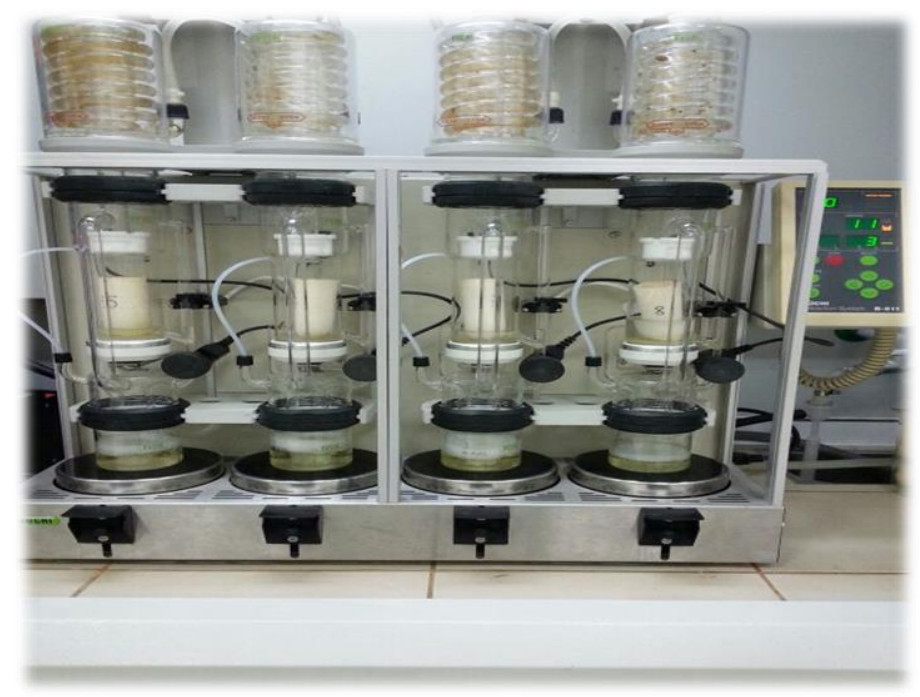

Şekil 5. Otomatik soksolet cihazı

\subsubsection{Yağ Asitleri Kompozisyonu}

Her bir türün meyve, meyve ve çekirdeklerinden elde edilen yağlardan $100 \mu$ lalınıp, $3 \mathrm{ml} \mathrm{N}$ Heptan ve $400 \mu \mathrm{l} 2 \mathrm{~N}$ metanollü $\mathrm{KOH}$ çözeltisi eklenerek esterleştirme uygulandıktan sonra yağlarının bileşenleri, Hatay Mustafa Kemal Üniversitesi, Ziraat Fakültesi Tarla Bitkileri Bölümü, Tıbbi ve Aromatik Bitkiler Analiz Laboratuvarında gaz-kromatogafik yöntem ile saptanmıştır. Sabit yağ bileşenlerinin belirlenmesi Thermo Scientific ISQ Single Quadrupole model gaz kromatogafi cihazı ile aşağıdaki şartlar altında gerçekleştirilmiştir. TG-Wax MS model, \%5 Phenyl Polysilphenylene-silohexane, $0.25 \mathrm{~mm}$ iç çap x $60 \mathrm{~m}$ uzunlukla, $0.25 \mu \mathrm{m}$ film kalınlığına sahip 
kolon kullanılmıştır. Taşıyıcı gaz olarak $1 \mathrm{~mL} /$ dak akış hızında helyum $(\% 99,9)$ kullanılmıştır. İyonizasyon enerjisi 70 eV, kütle aralığı m/z 1,2-1200 amu olarak ayarlanmıştır. Veri toplamada tarama modu (Scan Mode) kullanılmıştır. MS transfer line sıcaklığı $250^{\circ} \mathrm{C}$, MS İyonizasyon sıcaklığ $220^{\circ} \mathrm{C}$, Enjeksiyon port sicaklığ $220{ }^{\circ} \mathrm{C}$, kolon sıcaklığı başlangıçta $50^{\circ} \mathrm{C}$ olup $3^{\circ} \mathrm{C} /$ dak 1S1 artış oranı ile $220^{\circ} \mathrm{C}$ ye kadar yükseltilmiştir. Her bileşiğin yapısı Xcalibur progamı ile kütle spektrumları kullanılarak (Wiley 9) tanımlanmıştır.

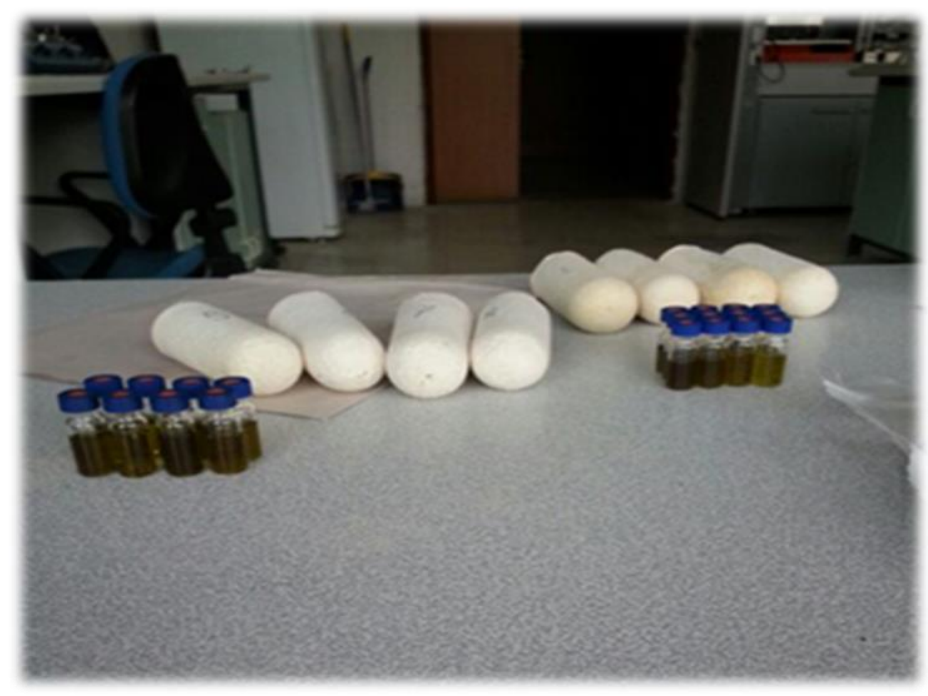

Şekil 6. Ekstraksiyon sonrası elde edilen defne sabit yağları

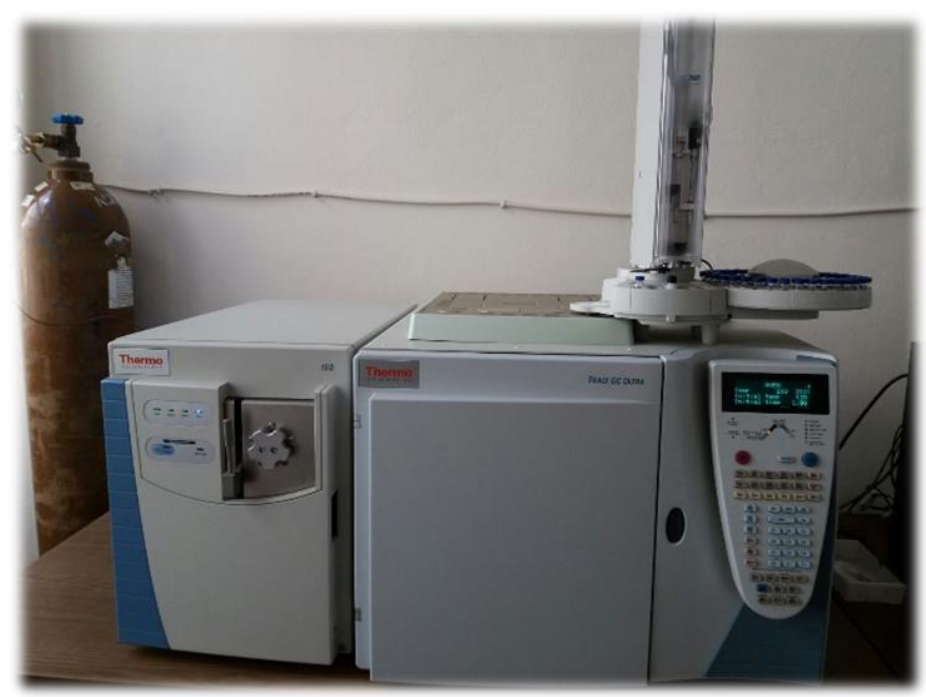

Şekil 7. Yağ analizlerinde kullanılan GC-MS cihazı 


\section{Bulgular ve Tartışma}

\subsection{Tüm Meyve Sabit Yağ Bileşenleri}

Hatay ilinde doğal olarak yetişen defne meyvelerinden elde edilen sabit yă ana bileşenlerinin; oleik asit $(\% 29,92-38,46)$, laurik asit $(\% 10,75-18,69)$, palmitik asit $(\% 16,31-21,97)$ ve linoleik asit (\%20,94 - 24,95) olduğu tespit edilmiştir (Tablo 2).

Yürütülen önceki çalışmalarda, Tanrıverdi ve ark. (1993) Silifke ve Hatay'dan temin ettikleri defne meyvelerinde oleik asit miktarı, \%35,7- \%34,2 olarak belirtirken, Ayanoğlu (2013) \%38,08 olarak belirlemiştir. Hafizoğlu ve Reunanen (1993), Tarsus ilçesinden temin edilen meyvelerde \%15,1; Çelik ve Y1lmaz (1996), İskenderun ilçesinden topladıkları meyvelerle \%39,17 olarak saptamışlardır. Ayanoğlu (2018) tarafından gerçekleştirilen diğer bir çalışmada oleik asit içeriği \%30,35 olarak belirlenmiştir. Nurbaş ve Bal (2005) tarafından gerçekleştirilen çalışmada defne meyvelerinde oleik asit içeriği \%39,6-40,2 ve Demirbaş (2010) tarafından Doğu Karadeniz bölgesinden temin edilen meyvelerle \%0,9 olarak belirlenmiştir.

Ege, Marmara, Karadeniz ve Akdeniz bölgelerinden 100 değişik lokasyondan elde edilen defne meyvelerinde \%24,22 ile \%64,81 arasında değișen oranlarda oleik asit bulunduğu bildirilmektedir (Karık ve ark., 2016). Maderina adasından temin edilen defne meyvelerinle oleik asit içeriği \%30 olarak bildirilmiştir (Castilhoa ve ark., 2005). Üç farklı yüksekliklerden (kıyı kesimlerinden, dağdan ve ova kesimlerinden) toplanılan meyvelerle sirasiyla \%43,10-34,38-36,39 olarak belirtilmektedir (Said ve Hussein, 2014). Çalışmamızdan elde edilen en yükssek oleik asit miktarı \%38,46 olarak belirlenmiştir ve tüm değerler incelendiğinde Karık ve ark. (2010)'nın \%64,81 olan oleik asit miktarından oldukça küçük, Hafizoğlu ve Reunanen (1993)'in oleik asit miktarından yüksek olduğu ve Ayanoğlu (2013) ile uyumlu olduğu görülmektedir.

Laurik asit miktarları incelendiğinde çalışmada elde edilen en yüksek laurik asit miktarı (\%18,64), Karık ve ark. (2010)'nın \%33,62 ve Hafizoğlu ve Reunanen (1993)'in \%54,2 olan laurik asit miktarından oldukça düşük bulunurken, Çelik ve Yılmaz (1996)'ın \%16,82, Nurbaş ve Bal (2005)'ın \%7,5-\%17,2, Ayanoğlu (2013)'nun \%16,57, Demirbaş (2010)'ın \%18,3, Tanrıverdi ve ark., (1993)'nın \%17,8- \%17,9, Castilhoa ve ark. (2005)'nın \%18, Said ve Hussein (2014)'in \%9,11-\%21,43-\%15,62 değerine yakın bulunmuştur. Karık ve ark. (2016)'nın Ege, Marmara, Karadeniz ve Akdeniz bölgelerinden 100 değişik lokasyondan alınan meyvelerle yapılan çalışmada elde edilen (\%10,28-\%33,62) değerleri arasında yer almaktadır.

Palmitik asit miktarları incelendiğinde; Silifke ve Hatay’dan temin edilen meyvelerle yapılan çalışmada Tanrıverdi ve ark. (1993) \%18,5- \%16,0; Ayanoğlu (2013) tarafında yapılan çalışmada 
\%18,57 olarak belirlenmiştir. Tarsus ilçesinden temin edilen meyvelerle yapılan araştırmada (Hafizoğlu ve Reunanen 1993) \%4,9; İskenderun ilçesinden temin edilen meyvelerle yapılan bir araştırmada (Çelik ve Yılmaz 1996), \%18,26, yapılan diğer bir çalışmada (Nurbaş ve Bal, 2005) \%2,5-24; Maderina adasından temin edilen meyvelerle yapılan çalışmada (Castilhoa ve ark., 2005) \%22,5, Doğu Karadeniz bölgesinden temin edilen meyvelerle yapılan çalışmada (Demirbaş, 2010) \%21,8-25,6, üç farklı coğrafi ve iklim bölgesinden (kıyıdan, dağdan ve ovadan) toplanılan meyvelerle yapılan çalışmada (Said ve Hussein 2014) \%19,48-15,48-20,51, Ege, Marmara, Karadeniz ve Akdeniz bölgelerinden 100 değişik lokasyondan elde edilen meyvelerle yapılan çalışmada (Karık ve ark., 2016) \%10,15-21,25 oranlarında palmitik asit bulunduğu bildirilmektedir. $\mathrm{Bu}$ araştırmadan elde edilen en yüksek palmitikasit miktarı \%21,97 olarak belirlenmiştir ve tüm değerler incelendiğinde Karık ve ark. (2010)'nın \%21,25 ve Demirbaş (2010)'ın 21,8'lik değerlerine yakın olup, Nurbaş ve Bal'ın (2005) \%24 ve Castilhoa ve ark. (2005) nın \%22,5 lik değerlerinden küçük, Çelik ve Yılmaz (1996), ın \%18,26 ile Ayanoğlu'nun (2013) değerinden büyüktür.

Linoleik asit miktarları incelendiğinde; Silifke ve Hatay'dan temin edilen meyvelerle yapılan çalışmada Tanrıverdi ve ark. (1993) \%23,4- \%26,0, Tarsus ilçesinden temin edilen meyvelerle yapılan araştırmada (Hafizoğlu ve Reunanen, 1993) \%17,2, İskenderun ilçesinden temin edilen meyvelerle yapılan bir araştırmada (Çelik ve Yılmaz 1996), \%19,96, yapılan diğer bir çalışmada (Nurbaş ve Bal, 2005) \%15,6-22,1, Maderina adasından temin edilen meyvelerle yapılan çalışmada (Castilhoa ve ark., 2005) \%20, Doğu Karadeniz bölgesinden temin edilen meyvelerle yapılan çalışmada (Demirbaş, 2010) \%20,05, üç farklı coğrafi ve iklim bölgesinden (kıyıdan, dağdan ve ovadan) topladıkları meyvelerle yapılan çalışmada (Said ve Hussein, 2014) \%24,492-25,06220,141, Ayanoğlu (2013) tarafinda yapılan çalışmada \%23,90 olarak belirlenmiştir.

Ege, Marmara, Karadeniz ve Akdeniz bölgelerinden 100 değişik lokasyondan elde edilen meyvelerle yapılan çalışmada (Karık ve ark., 2016) \%18,49-28,09 oranlarında linoleik asit bulunduğu bildirilmektedir. Çalışmamızdan elde edilen en yüksek linoleik asit miktarı \%24,95 olarak belirlenmiş ve tüm değerler incelendiğinde Said ve Hussein (2014)'in \%24,49, değerine yakın olup, Ayanoğlu (2013) \%23,90, Nurbaş ve Bal (2005) \%22,1 ve Castilhoa ve ark. (2005) nın \%20 ve Çelik ve Yılmaz (1996)'ın \%19,96 değerinden yüksek olmuştur. 
Koçer, O., ve Ayanoğlu, F., Uluslararası Doğu Anadolu Fen Mühendislik ve Tasarım Dergisi / International Journal of Eastern Anatolia Science Engineering and Design (IJEASED)

(2021) 3(1):72-88

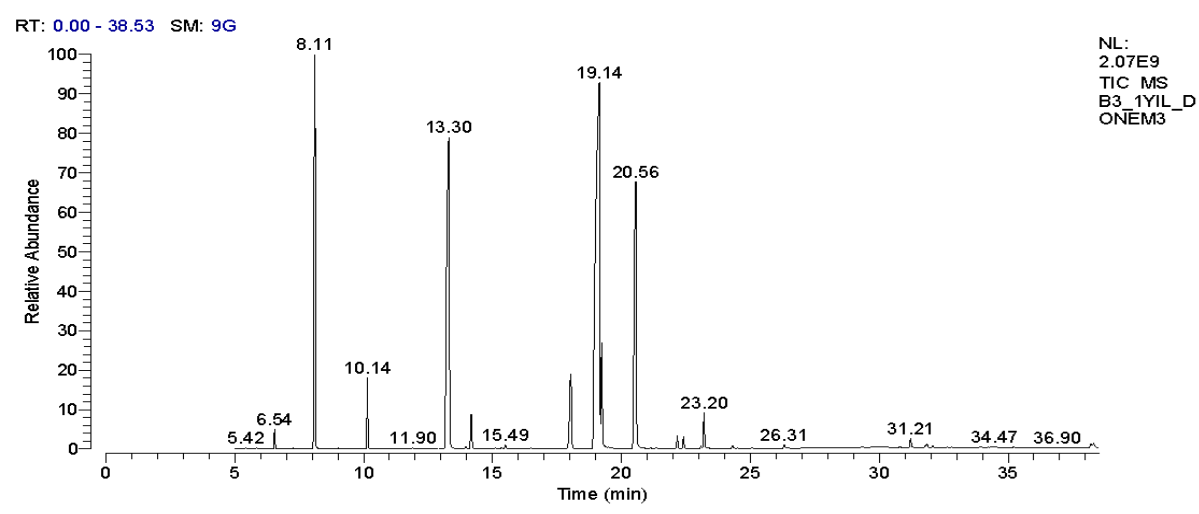

Şekil 8. Tüm meyve sabit yağ asitleri kromotogramı

Tablo 2. Tüm meyve sabit yağ ana bileşenleri (\%)

\begin{tabular}{|c|c|c|c|c|}
\hline Bitki kodu & Oleik asit & Laurik asit & Palmitik asit & Linoleik asit \\
\hline B3 & 35,26 & 15,78 & 18,50 & 21,67 \\
\hline B5 & 31,96 & 16,27 & 18,34 & 24,18 \\
\hline B26 & 30,29 & 18,69 & 17,38 & 23,93 \\
\hline HB5 & 31,11 & 14,79 & 19,12 & 23,71 \\
\hline HB7 & 33,29 & 14,87 & 18,81 & 23,30 \\
\hline HB10 & 31,59 & 11,34 & 20,96 & 24,95 \\
\hline ER12 & 32,08 & 14,84 & 19,74 & 20,94 \\
\hline ER13 & 33,12 & 13,88 & 18,10 & 23,82 \\
\hline ER14 & 35,83 & 14,61 & 16,91 & 20,96 \\
\hline ER16 & 36,12 & 14,13 & 17,06 & 21,31 \\
\hline ER17 & 32,19 & 16,05 & 18,83 & 21,18 \\
\hline ER24 & 31,90 & 15,59 & 20,87 & 22,61 \\
\hline ER42 & 30,34 & 16,10 & 21,92 & 24,06 \\
\hline K1 & 30,07 & 17,61 & 19,10 & 24,27 \\
\hline K2 & 35,96 & 13,09 & 20,32 & 22,09 \\
\hline K9 & 31,67 & 16,25 & 19,58 & 23,72 \\
\hline K13 & 36,38 & 10,75 & 21,79 & 22,52 \\
\hline SY9 & 29,92 & 15,16 & 21,97 & 21,91 \\
\hline SY12 & 33,79 & 16,36 & 17,73 & 23,42 \\
\hline YY4 & 33,85 & 16,13 & 17,76 & 24,69 \\
\hline YY9 & 36,68 & 12,89 & 16,93 & 22,17 \\
\hline YY10 & 38,46 & 12,24 & 18,14 & 21,08 \\
\hline ŞO1 & 36,84 & 14,08 & 19,17 & 23,23 \\
\hline ŞO2 & 30,13 & 16,33 & 20,43 & 24,67 \\
\hline YT1 & 37,70 & 15,40 & 17,59 & 23,19 \\
\hline YT2 & 38,38 & 15,83 & 16,31 & 23,57 \\
\hline O8 & 32,82 & 16,55 & 20,84 & 22,53 \\
\hline Ort. & 33,62 & 15,02 & 19,04 & 22,95 \\
\hline
\end{tabular}




\subsection{Meyve Eti Sabit Yă̆ Bileşenleri}

Hatay ilinde doğal olarak yetişen defne meyve etlerinden elde edilen sabit yağ ana bileşenlerinin incelendiği bu çalışmada; defne bitkisinin meyve eti sabit yağ ana bileşenlerinin oleik asit $(\% 34,31$ - 47,56), palmitik asit $(\% 20,18$ - 28,02) ve linoleik asit $(\% 21,29-29,30)$ olduğu tespit edilmiştir (Tablo 3).

Yapılan bazı çalışmalarda meyve eti yağındaki oleik asit miktarları incelendiğinde; Silifke ve Hatay'dan temin edilen meyvelerle yapılan çalışmada (Tanrıverdi ve ark., 1993), yăg asitleri oranlarının sırasıyla, oleik asit \%44-\%43,7, palmitik asit \%24,3-\%21,2, linoleik asit \%25,2-\%29,4 olduğu bildirilmiştir. Bu oranlar incelendiğinde oleik asit miktarlarının çalışmamızda elde edilen en yüksek değer olan \%47,56 oleik asit oranının altında, palmitik asit miktarlarının çalışmamızdaki en yüksek değer olan \%28,02 değerinin altında olduğu belirlenmiştir. Hatay’dan elde edilen meyve etlerinin linoleik asit miktarı çalışmamızla benzerlik gösterirken Silifke'den elde edilen meyve etlerinin linoleik asit miktarı çalışmamızdan elde edilen yüksek değerinin altında kalmıştır. Bu oranlar incelendiğinde oleik asit miktarlarının çalışmamızda elde edilen en yüksek değer olan \%28,42 oleik asit oranının altında olup, Beis ve Dunford'un (2006) oleik asit miktarlarının bu araştırmadan elde edilen değerlerden yüksek olduğu belirlenmiştir. Tanrıverdi ve ark. (1993) nın palmitik asit ve lioleik asit miktarları çalışmamızdaki en yüksek değerler olan \%12,70 ve \%28,67 değerlerinin altında olup, çalışmamızdan elde edilen laurik asit miktarı ise her iki bölgeden elde edilen laurik asit miktarlarından yüksek olarak belirlenmiştir.

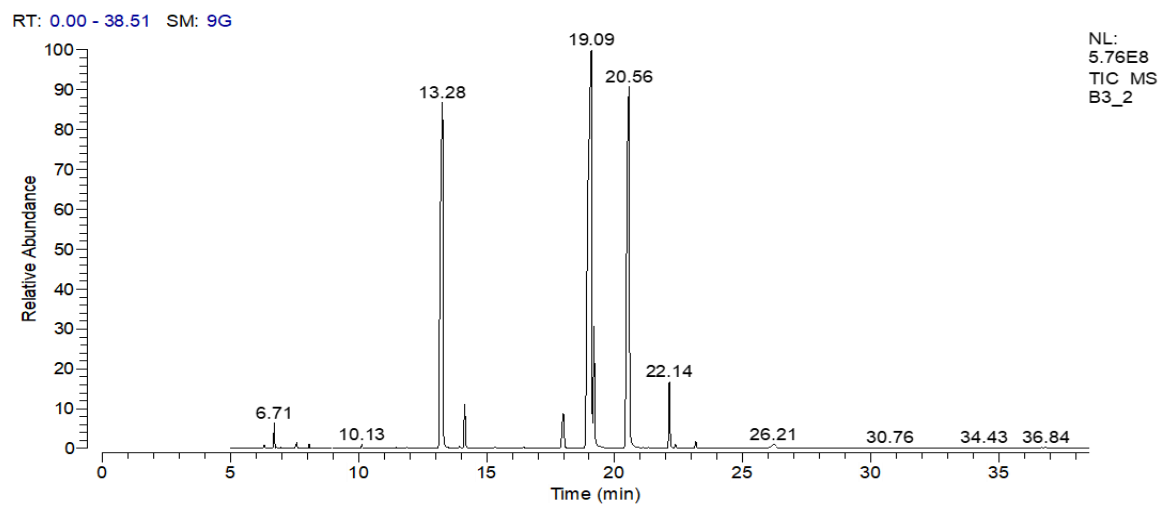

Şekil 9. Meyve eti sabit yağ asitleri kromotogramı 
Koçer, O., ve Ayanoğlu, F., Uluslararası Doğu Anadolu Fen Mühendislik ve Tasarım Dergisi / International Journal of Eastern Anatolia Science Engineering and Design (IJEASED)

(2021) 3(1):72-88

Tablo 3. Meyve eti sabit yağ ana bileşenleri (\%)

\begin{tabular}{|c|c|c|c|}
\hline Bitki kodu & Oleik asit & Palmitik asit & Linoleik asit \\
\hline B3 & 42,34 & 23,79 & 25,30 \\
\hline B5 & 38,44 & 26,81 & 26,84 \\
\hline B26 & 38,27 & 24,10 & 25,89 \\
\hline HB5 & 40,29 & 26,63 & 24,07 \\
\hline HB7 & 39,36 & 26,09 & 25,85 \\
\hline HB10 & 38,19 & 24,28 & 28,46 \\
\hline ER12 & 42,23 & 24,57 & 25,05 \\
\hline ER13 & 39,36 & 24,31 & 28,44 \\
\hline ER14 & 44,09 & 22,88 & 23,39 \\
\hline ER16 & 45,73 & 23,53 & 24,12 \\
\hline ER17 & 39,96 & 24,99 & 25,14 \\
\hline ER24 & 39,12 & 26,46 & 25,94 \\
\hline ER42 & 36,29 & 28,02 & 25,75 \\
\hline K1 & 43,72 & 22,63 & 24,14 \\
\hline K2 & 43,09 & 23,45 & 23,25 \\
\hline K9 & 38,95 & 26,08 & 26,30 \\
\hline K13 & 40,29 & 25,50 & 23,86 \\
\hline SY9 & 37,97 & 24,95 & 26,18 \\
\hline SY12 & 41,60 & 25,57 & 25,35 \\
\hline YY4 & 43,69 & 22,16 & 25,23 \\
\hline YY9 & 45,58 & 23,29 & 21,29 \\
\hline YY10 & 45,16 & 21,18 & 24,37 \\
\hline ŞO1 & 43,94 & 23,66 & 24,29 \\
\hline ŞO2 & 34,31 & 27,29 & 29,30 \\
\hline YT1 & 47,56 & 20,40 & 22,79 \\
\hline YT2 & 45,03 & 20,18 & 25,91 \\
\hline 08 & 39,21 & 26,34 & 23,54 \\
\hline ORT & 41,25 & 24,41 & 25,19 \\
\hline
\end{tabular}

\section{3. Çekirdek Sabit Yă̆ Bileșenleri}

Hatay florasında doğal olarak yetişen defne meyve çekirdeklerinden elde edilen sabit yağ ana bileşenlerinin incelendiği bu çalışmada, defne bitkisinin meyve çekirdeği sabit yă̆ ana bileşenlerinin oleik asit $(\% 20,58$ - \%28,42), laurik asit $(\% 22,25-\% 59)$ palmitik asit $(\% 9,72$ $\% 12,70)$ ve linoleik asit $(\% 22,22$ - \%28,67) olduğu tespit edilmiştir (Tablo 4).

Yapılan bazı çalışmalarda çekirdek yağındaki oleik asit miktarları incelendiğinde; Silifke ve Hatay'dan temin edilen meyvelerle yapılan çalışmada (Tanrıverdi ve ark., 1993), yağ asitlerinin sirasıyla, oleik asit (\%12 - \%21,8), laurik asit (\%63 - \%45), palmitik asit (\%5,23-\%6,65), linoleik asit $(\% 25,20-\% 23,1)$ olduğu, Muğla'dan temin edilen çekirdeklerle yapılan çalışmada (Beis ve 
Dunford, 2006), oleik asit $(\% 37,2$ - \%37,3), laurik asit $(\% 43,1-\% 44,8)$, ve linoleik asit $(\% 14,7-$ $\% 13,3)$ olduğu bildrilmiştir.

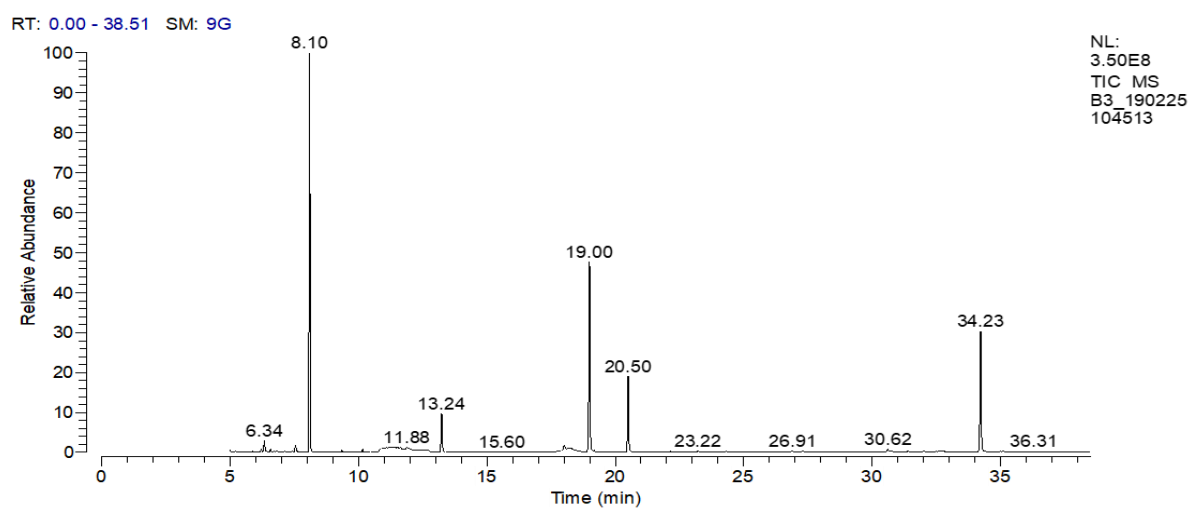

Şekil 10. Çekirdek sabit yağ asitleri kromotogramı

Tablo 4. Çekirdek sabit yağ ana bileşenleri (\%)

\begin{tabular}{|c|c|c|c|c|}
\hline Bitki kodu & Oleik asit & Laurik asit & Palmitik asit & Linoleik asit \\
\hline B3 & 26,34 & 23,65 & 12,54 & 25,68 \\
\hline B5 & 25,71 & 23,06 & 10,54 & 25,37 \\
\hline B26 & 27,43 & 24,21 & 11,49 & 25,63 \\
\hline HB5 & 25,11 & 23,35 & 10,37 & 23,69 \\
\hline HB7 & 25,78 & 24,00 & 10,24 & 25,76 \\
\hline HB10 & 21,22 & 26,41 & 10,90 & 24,04 \\
\hline ER12 & 22,94 & 24,12 & 11,44 & 25,34 \\
\hline ER13 & 26,68 & 24,48 & 12,70 & 24,35 \\
\hline ER14 & 22,65 & 26,51 & 11,34 & 25,02 \\
\hline ER16 & 24,76 & 24,60 & 10,27 & 22,37 \\
\hline ER17 & 25,54 & 26,59 & 12,13 & 22,45 \\
\hline ER24 & 24,03 & 23,47 & 11,39 & 23,87 \\
\hline ER42 & 26,67 & 23,08 & 11,20 & 23,85 \\
\hline K1 & 22,50 & 26,49 & 10,04 & 22,22 \\
\hline K2 & 24,03 & 25,10 & 10,38 & 24,05 \\
\hline K9 & 23,66 & 25,39 & 10,45 & 23,71 \\
\hline K13 & 25,31 & 22,46 & 9,72 & 25,79 \\
\hline SY9 & 20,66 & 24,03 & 10,79 & 28,44 \\
\hline SY12 & 20,58 & 23,91 & 10,53 & 28,67 \\
\hline YY4 & 25,65 & 24,17 & 11,46 & 24,47 \\
\hline YY9 & 26,83 & 24,68 & 10,08 & 23,49 \\
\hline YY10 & 27,84 & 23,99 & 10,55 & 24,00 \\
\hline ŞO1 & 28,35 & 22,25 & 9,83 & 23,95 \\
\hline ŞO2 & 28,42 & 24,08 & 10,00 & 23,81 \\
\hline YT1 & 25,77 & 23,96 & 9,90 & 24,65 \\
\hline YT2 & 26,39 & 23,41 & 10,98 & 25,24 \\
\hline 08 & 25,50 & 24,25 & 10,27 & 23,99 \\
\hline ORT & 25,05 & 24,29 & 10,80 & 24,59 \\
\hline
\end{tabular}




\section{Sonuçlar ve Öneriler}

Defne tüm meyve ve çekirdek sabit yağları incelendiğinde ana bileşenlerinin laurik asit, oleik asit, palmitik asit ve linoleik asit olduğu belirlenmiştir. Meyve etinde ise bu bileşenlerden laurik asitin bulunmadığı belirlenmiştir.

Tüm meyveden elde edilen sabit yağ bileşenleri incelendiğinde; en yüksek oleik asit miktarı \%38,46 ile YY10, en yüksek laurik asit miktarı \%18,69 ile B26, en yüksek palmitik asit miktarı \%21,97 ile SY9, en yüksek linoleik asit miktarı \%24,95 ile HB10 genotipi olarak belirlenmiştir.

Meyve etinden elde edilen sabit yağ bileşenleri incelendiğinde; en yüksek oleik asit miktarı \%47,56 YT1, en yüksek palmitik asit miktarı \%28,02 ile ER42, en yüksek linoleik asit miktarı \%29,30 ile ŞO2 genotipi olarak belirlenmiştir.

Çekirdekten elde edilen sabit yağ bileşenleri incelendiğinde; en yüksek oleik asit miktarı \%28,42 ile ŞO2, en yüksek laurik asit miktarı \%26,59 ile ER17, en yüksek palmitik asit miktarı \%12,70 ile ER13, en yüksek linoleik asit miktarı \%28,67 ile SY12 genotipi olarak belirlenmiştir.

Defne meyve yağında önemli bir seçim kriteri olan Laurik asit bileşeni açısından genotipler incelendiğinde en yüksek Laurik asit içeriği B26 genotipinde elde edilmiştir. Oleik asit içeriği açısından genotipler değerlendirildiğinde YY10 genotipi ön plana çıkmıştır. Meyve yağı ve yaprak yağı açısından seçilen genotiplerin tescil edilmesi ve yetiştiriciliğinin yapılması ile doğal floradan kontrolsüz toplamanın önüne geçilmesi ve yağ kalitesinde standardizasyonun yakalanması mümkün olacaktır.

\section{Yazarların Katkısı}

Çalışmada her iki yazar da eşit oranda katkı sunmuştur.

\section{Çıkar Çatışması Beyanı}

Yazarlar arasında herhangi bir çıkar çatışması bulunmamaktadır.

\section{Araştırma ve Yayın Etiği Beyanı}

Yapılan çalışmada, araştırma ve yayın etiğine uyulmuştur.

\section{Teşekkür}

Yazarlar, Hatay Mustafa Kemal Üniversitesi BAP birimine, 17.D.003 proje numaras1 ile ikinci yazar danışmanlığında birinci yazar tarafından hazırlanan doktora tezinin bir kısmından üretilen bu çalışmaya, destekleri için teşekkür ederler. 


\section{Kaynaklar}

Anonim, (2004). T.C. Türkiye Ormanlarında Odun Dışı Ürünler, Çevre ve Orman Bakanlığı Orman Genel Müdürlüğü, Ankara.

Anonim, (2016). Defne Eylem Planı 2016-2020, T.C. Orman ve Su İşleri Bakanlığı Orman Genel Müdürlüğü, Ankara.

Ayanoğlu, F., Mert, A., Kaya, A., ve Köse, E. (2010). Hatay Yöresinde Doğal Olarak Yetişen Defne (Laurus nobilis L.) Bitkisinin Kalite Özelliklerinin Belirlenmesi ve Seleksiyonu, Tübitak Proje No: 108O878, 268s, Hatay.

Ayanoğlu, F., Kaya, D. A., Mert, A., and Köse, E. (2013). Determination of Quality Aspects and Selection of Natıve Grown Laurel (Laurus nobilis L.) in Hatay Province of Turkey. Mesmap-2013. 58.

Ayanoğlu, F., Kaya, D. A., Koçer, O., (2018). Promising Bay Laurel (Laurus nobilis L.) Genotypes for Fruit Production. International Journal of Chemistry and Technology. 2(2): 167-161.

Beis, S.H., and Dunford, N.T. (2006). Supercritical Fluid Extraction of Daphne (Laurus nobilis L.) Seed Oil. JAOCS, Vol. 83, no. 11, 953-957.

Castılhoa, P. C., Costaa, M., Rodriguesb, A., and Partıdár1oc, A. (2005). Characterization of laurel fruit oil from Madeira Island, Portugal. Jaocs, Vol. 82, no. 12 pg 863-867.

Çelik, S., ve Y1lmaz, Ö. (1996). Defne (Laurus nobilis L) yaprak ve meyvesinin yağ asitleri bileşimi. The journal of food, 21 (3): 165-167.

Davis, P. H. (1982). Flora of Turkey, Vol. 7, Edinburg Universty Pres, 947p., Edinburg.

Demirbaş, A. (2010). Biodisel from Bay Laurel Oil via Compressed Methanol Transesterification. Energy Sources, Part A, 32:1185-1194.

Duke, J. A. (1987). CRC Handbook of Medicinal Herbs, CRC Pres inc., 677p., Florida, U.S.A.

Duke, J. A. P. A. K. Duke., L. Judith, Cellie J. L. Du., (2008). Duke's Handbook of Medicinal Plants of the Bible CRC press s. 237-240, USA.

Ercan, A.S. (1983). Defne Yaprağı ve Yağının İhracatı Geliştirmesi. İhracatı Geliştirme Etüd Merkezi Yayınları No: 74 s.2-9.

Hafizoglu, H., and Reunanen, M. (1993). Studies on the Components of Laurus nobilis L. from Turkey with Special References to Laurel Berry Fat. Lipid-Fett., 95:304--308.

Karık, Ü., Çiçek, F., Oğur, E., Tutar, M., and Ayas, F. (2016). Türkiye'de Yayılış Gösteren Defne (Laurus nobilis L.) Popülasyonlarının, Meyve Özellikleri. Ege Tarımsal Araştırma Enstitüsü Dergisi, 26 (1): 1 -16 .

Konukçu, M. (2001). Ormanlar ve Ormancılığımız. Devlet Planlama Teşkilatı Yayın ve Temsil Dairesi Başkanlığı, Yayın No. DPT: 2630, $258 \mathrm{~s}$.

Nurbaş, M. ve Bal, Y. (2005). Recovery Of Fixed And Volatile O1ls From Laurus Nobilis L. Fruit And Leaves By Solvent Extraction Method. Eskişsehir Osmangazi Üniversitesi Mühendislik ve Mimarlı Fakültesi Dergisi, 18 (2), 15-24.

Said, C. M., and Hussein, K. (2014). Determination of the Chemical and Genetic Differences of Laurus collected from Three Different Geographic and climatic areas in Lebanon. European Scientific Journal, 1857- 7431.

Şafak, İ., ve T, Okan. (2004). Kekik, defne ve çam fistığının üretimi ve pazarlaması, Doğu Akdeniz Ormancılık Araştırma Müdürlüğ̈̈ DOA Dergisi, 10: 101-129.

Tanrıverdi, H., Tunçel, M., ve Başer, K. (1993). Defne meyvesi sabit yağının ekstraksiyon verim ve kalitesinin belirlenmesi üzerine bir çalışma. Journal of Pharmaceutical Sciences, 18,107-113. 